\title{
Defining Sustainability in Afghanistan's Built Environment: A Case Study of World Bank Building in Kabul and Comparative Analysis of Prominent Literature
}

\author{
Mahsa Khatibi*, Khairul Anwar Mohamed Khaidzir, Aiman Mohd Rashid \\ Department of Architecture, Faculty of Built Environment and Surveying, University Teknologi Malaysia, Skudai 81310, \\ Johor, Malaysia
}

Corresponding Author Email: khatibi.mahsa@graduate.utm.my

https://doi.org/10.18280/ijdne.160303

Received: 13 May 2021

Accepted: 15 June 2021

\section{Keywords:}

sustainable design, sustainable building, LEED-certified building, Afghanistan

\begin{abstract}
The built environment is one of the critical areas of intervention for sustainable development. This study aims to investigate the sustainable and appropriate ways of designing Afghanistan's built environment. To put forward a reliable mechanism of research, the study develops and uses three approaches. The first is to review the sustainable strategies applied in the design of the country's first LEED-certified building, the World Bank Building in Kabul (WBBK). Secondly to understand the main concepts involved in the practice of designing for sustainability by analyzing five of the most influential books in the realm of design and sustainability. Finally, the findings from the review of the five books are reinforced with more literature associated with design and sustainability to analyze and evaluate the sustainable strategies of the WBBK. The study posits that although the building can promote the idea of a sustainable built environment in the country but there are several issues. Among the issues are, (1) Its high dependence on eco-technologies to reduce environmental impact rather than designing in relation to social and ecological systems, (2) Its insufficiency in providing a resilient design that is self-sufficient, flexible, and adaptive, and (3) Its lack of creating aesthetic experiences and cultural meaning for its occupants which are required for future designs and development. Furthermore, based on the findings and upon inquiring into the sustainable design of WBBK, the paper concluded with a set of recommendations to contribute towards the design of a sustainable built environment in Afghanistan.
\end{abstract}

\section{INTRODUCTION}

Sustainable Development has been a major global debate since the United Nations Commission report on Environment and Development, known as the Brundtland Report, published in 1987 [1, 2]. However, the initiation of Sustainable Development Goals (SDGs) in 2015, marked a global milestone to call for a shift towards better solutions to issues concerning sustainability and resiliency, considering the needs of people in the developing nations $[1,3]$.

A sustainable built environment can have a significant impact on the achievement of Sustainable Development Goals. With the global commitment to achieve the UN SDGs, the issue of designing for sustainability has become more important than ever. This can be clearly seen in the definition of SDG11 which is related to the built environment:

'Sustainable development cannot be achieved without significantly transforming the way we build and manage our urban spaces. The rapid growth of cities - a result of rising populations and increasing migration-has led to a boom in mega-cities, especially in the developing world, and slums are becoming a more significant feature of urban life.

Making cities sustainable means creating career and business opportunities, safe and affordable housing, and building resilient societies and economies. It involves investment in public transport, creating green public spaces, and improving urban planning and management in participatory and inclusive ways.' (Goal 11: Sustainable cities and communities | UNDP, 2020).

Afghanistan, as a UN member state, is committed to the achievement of sustainable development goals. However, the country is currently at the stage of its infancy in implementing sustainability in the built environment. In 2019, Afghanistan witnessed its first LEED-certified building. LEED (Leadership in Energy and Environmental Design) is a green building rating system developed under the scope of the World Green Building Council (WGBC) and is used to assess the sustainability of buildings [4]. The new office building in Kabul, World Bank Building (WBBK) was awarded the LEED $\mathrm{BD}+\mathrm{C}$ Gold rating as well as the "LEED Earth Award" for its contribution towards the promotion of sustainability [5]. This is the country's first LEED-certified building and is considered an important milestone towards the achievement of sustainability in Afghanistan's built environment.

As discussed by Baumann et al. [6], there is a range of methodologies, strategies, and tools that deal with environmental issues and assessments in design practice. However, the scope of sustainable design has broadened and evolved through the years, from an objective and scientifically measurable environmental concept to a subjective and socially embedded, and contextually dependent term. That is, from solely depending on environmental technologies to reduce environmental impact towards considering human involvement in the process of decision-making [6-10]. 
Whereas with more than 100 definitions that have appeared for the term sustainability over the past decades, it remains an important matter of exploration and inquiry but uncertainties on how to implement sustainable principles in practice and to adopt them in sustainable building projects still continue [7, 11-14].

Victor Papanek is one of the most influential actors in the realm of sustainable design. Papanek calls for humanitarian and ecological design as he believed that design should aim to serve the poor and those who are in need [15]. Fisher [16] and Papanek [15] emphasize quality rather than quantity. They define quality as a means of reinforcing emotional bonding and mutually beneficial relationships. Similarly, Fry [17] recommends that design address major global issues of climate change and inequity in order to resolve the current challenges and to adapt to the problems that we are unable to solve. $\mathrm{He}$ suggests a transformational change in human behavior on an ethical basis. On the other hand, Walker [18] and DeKay [19] put an emphasis on personal experiences and the cultural meaning of design as much as on the attention towards quantitative issues. Whereas both writers discuss different approaches for design. While Walker [18] believes in a modest design with minimum intervention, DeKay's [19] idea rests on building upon the technological solutions for sustainability to include ecological patterns of the context and further to create rich experiences and symbolic meaning for humans.

Subsequently, there are various concepts regarding the design for sustainability, however, these concepts do share some common criteria such as the use of technology, ethics, and social interplay [9].

On the other hand, sustainability is implemented at various levels in design disciplines, while some thinkers call for major transformative design through cultural changes affecting consumptive behavior to address the global environmental and social issues; others may suggest introducing new building types to create value for users; while some practices may implement technological add-ons to the existing buildings affecting only the product level (i.e., incremental changes) [20].

However, despite the complexity associated with the implementation of sustainability, countries need to adopt effective plans and spur actions in areas crucial to sustainable development. Therefore, this paper aims to seek methods of designing an appropriate and sustainable built environment for Afghanistan. This is achieved by studying the sustainable strategies in the design of the WBBK and analyzing the five publications (books) on the topic of sustainability and design. The study further analyzes and evaluates the design of the WBBK in the light of these publications to draw conclusions for designing a sustainable built environment for the context of Afghanistan.

\section{METHOD OF STUDY}

The study begins by reviewing the sustainable strategies adopted in the WBBK. This is done by categorizing the sustainable strategies according to Shao's study of sustainable strategies in commercial buildings in Australia [21] and then classifying them for social and environmental quality based on the categories defined by Wen et al. [22] in their unified framework of sustainable building. The study of WBBK has helped to understand the current application of sustainable design in the built environment of Afghanistan.
Secondly, five of the most significant works in the realm of designing for sustainability spanning from the $20^{\text {th }}$ century to the $21^{\text {st }}$ century were analyzed and compared (Table 1 ). This has contributed to determining the main concepts in the practice of designing for building sustainability. The books were identified through the first author's research on design and sustainability as part of her doctoral study. However, three criteria guided the selection of the books in this study:

1. Accentuation of the design's potential role to address sustainability.

2. The book author's productivity in the field of sustainable design.

3. The introduction of a new theory or concept.

Finally, the sustainable strategies implemented in WBBK are studied in the context of these findings and reinforced with further literature on sustainable design. This part has been performed to analyze and evaluate the sustainable design of the WBBK and to draw upon it to recommend future considerations for the design of a more appropriate sustainable built environment for the country.

Table 1. List of the books reviewed

\begin{tabular}{|c|c|c|c|}
\hline No. & Title & Author & $\begin{array}{c}\text { Year } \\
\text { Published }\end{array}$ \\
\hline 1 & $\begin{array}{c}\text { Design for the Real World: } \\
\text { Human Ecology and Social } \\
\text { Change }\end{array}$ & $\begin{array}{l}\text { Victor } \\
\text { Papanek }\end{array}$ & 1971 \\
\hline 2 & $\begin{array}{l}\text { Architectural Design and } \\
\text { Ethics: Tools for Survival } \\
\text { Design Futuring: }\end{array}$ & $\begin{array}{l}\text { Thomas } \\
\text { Fisher }\end{array}$ & 2008 \\
\hline 3 & $\begin{array}{c}\text { Sustainability, Ethics and } \\
\text { New Practice }\end{array}$ & Tony Fry & 2009 \\
\hline 4 & $\begin{array}{c}\text { Integral Sustainable: } \\
\text { Transformative Perspectives } \\
\text { Design }\end{array}$ & $\begin{array}{c}\text { Mark } \\
\text { DeKay }\end{array}$ & 2011 \\
\hline 5 & $\begin{array}{l}\text { Designing Sustainability: } \\
\text { Making Radical Changes in a } \\
\text { Material World }\end{array}$ & $\begin{array}{c}\text { Stuart } \\
\text { Walker }\end{array}$ & 2014 \\
\hline
\end{tabular}

\section{WORLD BANK BUILDING KABUL (2019)}

\subsection{Background of the World Bank Building Kabul}

The building for World Bank Kabul (Figure 1), was designed by En3 Sustainability Solutions, an India-based sustainable design, and engineering consulting firm. The construction of the project begun in 2016 and was completed in 2019. It received a LEED BD+C Gold rating, in the same year, as well as a LEED Earth Award.

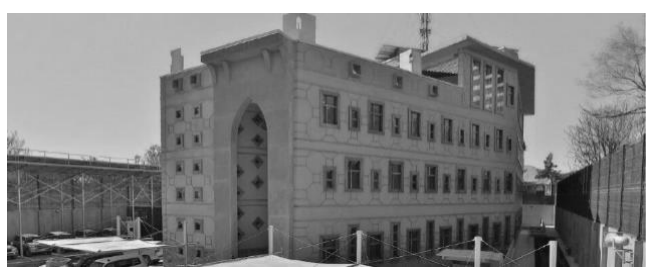

Figure 1. World Bank Building Kabul (Source: https://www.gbci.org)

LEED Earth is a campaign initiated by the United States Green Building Council (USGBC) that offers the certification of the first project at no cost. It aims to promote sustainable building and to increase the uptake of LEED throughout the 
world. Moreover, LEED BD $+\mathrm{C}$ is the USGBC's rating system at the building level [23]. A building receives a certified rating if it earns at least 40 points, a silver rating for 50 points, gold for 60 points, and platinum for 80 points [24].

The project carries certain measures to achieve sustainability through the green design $[5,25]$. Table 2 provides basic information about the project.

Table 2. World Bank Building Kabul

\begin{tabular}{cc}
\hline Information & Description \\
\hline Year commenced: & November 2016 \\
Year of completion: & January 2019 \\
Project type (occupation): & Office \\
Developer: & En3 Sustainability Solutions \\
Built-up Area: & 68316 sq.ft \\
Project Location: & Kabul, Afghanistan \\
\hline
\end{tabular}

\subsection{Sustainable strategies applied in the World Bank Building Kabul (2019)}

When defining the sustainable strategies in a building; Shao [21] categorized them in three sets of "architectural structure", "building elements and materials" and "utility services and maintenance". Wen et al. [22] analyzed the three sustainability pillars (environmental, social, and economic) in different Green Building Rating Tools (GBRT) and provide a new unified criteria framework based on the different GBRTs. The sustainable strategies applied on WBBK, as mentioned by the developers in their website [25], are first categorized according to Shao [21] and then classified for social and environmental quality based on the classification performed by Wen et al. [22] in their unified framework (Table 3).

Table 3. Sustainable building strategies in WBBK

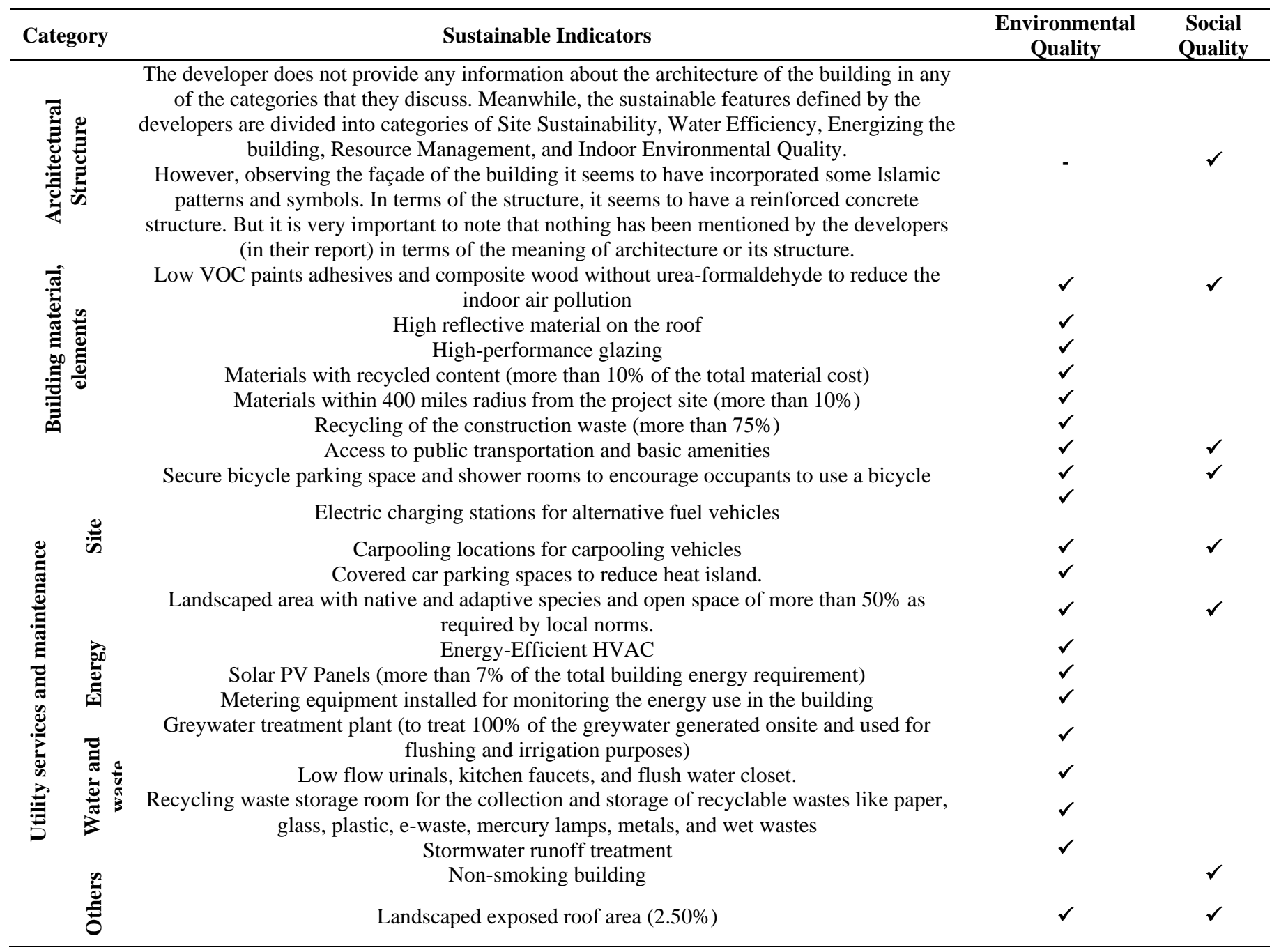

\section{ANALYSIS OF THE FIVE BOOKS ON DESIGNING FOR SUSTAINABILITY}

The scope of designing for sustainability has been broadened [6]; different thinkers provide different approaches and various opinions. Whereas there is no doubt that designing for sustainability has been evolving through the years. That is from being an objective and scientifically measurable concept to a subjective and socially embedded and contextually dependent issue [7-9]. The following paragraphs will explain the analysis from five of the most influential books in the realm of design and sustainability (Table 1 ).

\subsection{Design for the Real World: Human Ecology and Social Change by Victor Papanek (1971)}

Victor Papanek, one of the most influential thinkers in the realm of sustainable design calls for humanitarian and ecological design [15]. He recalls design as an integrated process and proposes a six-sided framework for sustainable 
design. The framework includes method, use, need, telesis, association, and aesthetics. Papanek proposes to design for the genuine needs of people versus the "artificially created wants" and to integrate the tools, processes, and materials in a creative and honest way, doing the most with the least. In his framework, he defines "telesis" as the ability of the design to fit in its socio-economic context in a way that expresses the time and conditions that have led to its creation. He provides an example of how the use of "tatami" depends on place and time; "increasing use of regular shoes and industrial precipitation make the use of tatami difficult enough in Japan and absolutely ridiculous in the United States, where high cost makes periodic disposal and reinstallation ruinously expensive". Similarly, he seeks aesthetics in the meaning of a design rather than its superficial appearance. For him, aesthetics is an intrinsic part of function; "The streamlining of a trout's body is aesthetically satisfying to us, but to the trout, it is a by-product of swimming efficiency".

He believes that designers must make moral and social judgments before they begin to design. Criticizing the design of automatic gear shift in cars, he states: “... a good example of such wasted energy is the automatic gear shift. The actual energy expended by the driver when shifting gears is incomparably smaller than the energy expended in manufacturing the automatic shift, not to mention the energy required to supply the factory and the automobile with the additional raw materials and man-hours required to make it".

\subsection{Architectural Design and Ethics: Tools for Survival by Thomas Fisher (2008)}

Another influential design thinker is Thomas Fisher [16]. For him also, design is a meaningful action that focuses to serve people and those who are in need, with optimal choices. In his book, Architectural Design and Ethics; Tools for Survival, he talks about design ethics that are needed to overcome the global catastrophe generated by humans. He claims that the damage we have caused on earth cannot be solved in the way we created it; and along with resource efficiency measures and the use of new technologies we need to appreciate human wisdom as well. That is by helping others and living a modest life. According to Fisher, designers need to change their values, and as much as they think about the needs of an individual (client) they must think about the community, the future generations, and all the ecosystems. Fisher requires the balancing of the specific needs of a project with its larger context, i.e., the various aspects of our environments such as the physical, the political, the ethical, and the social environment. He calls for relearning the culture and tradition of native populations to understand their approach to design for resilience in harsh conditions and build upon them for our future.

\subsection{Design Futuring: Sustainability, Ethics and New Practice by Tony Fry (2009)}

As with Papanek, Fisher also believes in distinguishing between real versus false needs. In this realm, Fry [17] proposes a "redirective" design practice, which he believes increases the importance and "futuring" capability of the design. The redirective design fills the gap between multiple disciplines for a relational assessment of a project and considers the consequences of design action (over a period of time) in the world; it negates to view the design practice as a superficial activity in terms of appearance and performance.

He describes two aspects of "redirective design" practice, namely "elimination" and "recoding". For example, "Having the heating and cooling systems of office buildings set to deliver $22^{\circ} \mathrm{C}$ all year round so that men in suits will be thermally comfortable is simply energy irresponsible. Temperature settings should be based on people dressing according to the weather". In this regard, Fry's view surpasses that of Papanek, where Papanek calls for a transformation of products to consider the needs of underdeveloped countries; Fry calls for elimination and recoding of products, as he proposes "to mobilize knowledge of the past and present to create culturally and materially situated needs that marginalize or displace imported wants".

Both Fisher and Fry believe in learning from the past to build for the future. However, while Fisher gives more importance to the past approaches; Fry believes in methodological learning from the historic reflections to plan for the future and design for the present, "how the homeless and abject poor find social and economic ways to survive, the expertise they develop and their ability to 'design with the designed' must all be treated as a repository of futuring knowledge". The outcome of this operation could have a significant effect on how a product is made, where it is produced, how it is represented, how its effects are perceived, and whether it should be produced or not [17].

Papanek, Fisher, and Fry, all three believe in the fact that appropriate reactions to overcome the global challenges will vary from place to place; as Fry calls sustainable action a matter of place, time, and circumstances.

Fry and Fisher both talk about giving importance to quality rather than quantity. Fry defines quality products as products that may cost more but are durable or have a useful and nondamaging afterlife; products that care for their users and the environment, things that replace the existing machines and are easy hand tools. For a better future for humanity, he requires to resolve the current environmental problems as much as possible, adapt to and design for the problems that we are unable to solve (e.g., the designs in Australia should consider the current water scarcity in the region) and to transform the self that requires structural changes in a person's life.

\subsection{Designing Sustainability: Making Radical Changes in a Material World by Stuart Walker (2014)}

In the debate of disposal design and consumer-oriented design practice versus responsible design that requires ethical judgment, considers the need of people, depends on the place, and requires a transformation in human behavior, Walker [18] also shares ground with Papanek, Fry, and Fisher. He proposes the "quadruple bottom line of sustainability" for the design discipline that comprises of the three meanings namely practical meaning, social meaning, personal meaning, and economic means. Economic consideration is defined to act as means to achieve the three meanings. He defines his approach as one that considers values and ethical judgments (spiritual values) to design for practical needs (quantitative methods) that cares for social issues (mostly qualitative methods), i.e., "a basis for doing the right thing and constructing what might be termed a meaningful life, and for making a meaningful contribution to society".

He recalls for an environmentally responsible and socially just design, where every decision in production is concerned with impact and meaning. A design that is modest, enduring, 
creative, useful, meaningful, has minimum intervention (least resource consumption), and appreciates Nature's beauty.

Walker puts special emphasis on the meaning of a product (by using symbolism and connection to Nature) and its connectedness to people to address the deep human perceptions. "By combining direct, personal awareness of the material at hand with the spontaneously 'felt', the features and innate properties of the material are retained. Through its visual and tactile qualities, the design is a tangible, lightly modified memento of Nature, reminding us of our closeness to the earth and our dependence on its provision".

The tendency of Walker towards nature is like Papanek; however, while Papanek addresses the mimicry of Natural procedures to improve the current technologies in design; Walker calls for the display of nature in design as a means to inform the importance of human's connectedness to nature.

\subsection{Integral Sustainable: Transformative Perspectives Design by Mark DeKay (2011)}

As with Walker, DeKay [19] also puts a special emphasis on personal experiences and cultural meaning. He proposes a four-nexus framework for sustainable design. He believes that the four perspectives on "1. How Sustainable Design performs; 2. How Sustainable Design is also an ecosystem; 3. How Sustainable Design creates beauty and deep human feeling; and 4. How Sustainable Design conveys cultural meaning" are critical to the overall success of Sustainable design and if any of these perspectives is left out; it will weaken the effectiveness of Sustainable Design and may end in a failure.

Dekay's design approach for sustainability builds on the Technological Sustainability and expands it to include the ecological context of the study, to create rich experiences for the users through revealing and expressing sustainable technology (so that cycles of Nature are experienced by people and a relationship is created between people and Nature), and to encode cultural meaning that can communicate with people.

As a result, Dekay's approach to addressing sustainable design in buildings is more environmentally inclined whereas Papanek, Fry, and Walker's approaches are socially inclined expecting ethical behavior from humans and designers. Consequently, Papanak calls for a transformation of technologies by designers to account for the needs of the poor; Fry asks for a "redirective design" by designers aiming to impact human behavior and their priorities, while Fisher and Walker favor a modest design with minimum intervention in nature.

\section{WORLD BANK BUILDING KABUL AND THE LITERATURE ON DESIGN AND SUSTAINABILITY}

\subsection{Criteria of a sustainable design}

As evident from the previous section, the most important considerations regarding design and sustainability are "ethical" as defined by Papanek, Fry, Fisher, and Walker and, "social" and "environmental" as described by all the five thinkers. This merges with Keitsch's [9] definition of the three most important criteria that consolidate the trending concepts in the theory of sustainable design as "ethics, technology fixes, and social interaction". She justifies her definition of the three criteria with Aristotle's three active disciplines, i.e., "theoria wisdom/knowledge, praxis - political action, and poesis - production/ technology". The ethical criteria point towards the moral responsibility of the designer to create socially just and environmentally responsible design. For example, Papanek's emphasis on designing for people's genuine needs, Fisher's idea of considering the impact of the design on future generations and ecosystem, Fry's redirective design approach, and Walker's stress on minimal resource consumption, all require an ethical approach on behalf of the designer. Similarly, the technology fixes criteria refer to the quantitative and empirical approaches towards solving environmental problems. However, according to four of the five thinkers, the use of technologies should be accompanied by the ethical judgment of the designer. Finally, social interaction requires the participation of different stakeholders [7] to understand from physical needs to the emotional and symbolic needs of people and to create a stable society. For instance, creating rich experiences and cultural meaning for people, according to DeKay and Walker, is based on the criteria of social interaction. Keitsch proposes consideration and integration of all the three criteria rather than overemphasizing one or marginalizing the others.

However, as observed in the case of World Bank Building Kabul, most of the sustainable design strategies gave significance towards quantitative objective methods to design for the environmental concerns, i.e., "technology fixes" as defined by Keitsch [9] (Table 2). There are only a few social aspects considered that relate to the physical needs of the users and thus marginalize the emotional and cognitive constraints. Hence, this is a significant issue that needs consideration in future designs. The following sections describe the five subcriteria important to meet the ethical, environmental, and social criteria. The framework for analysis of the WBBK is presented in Figure 2

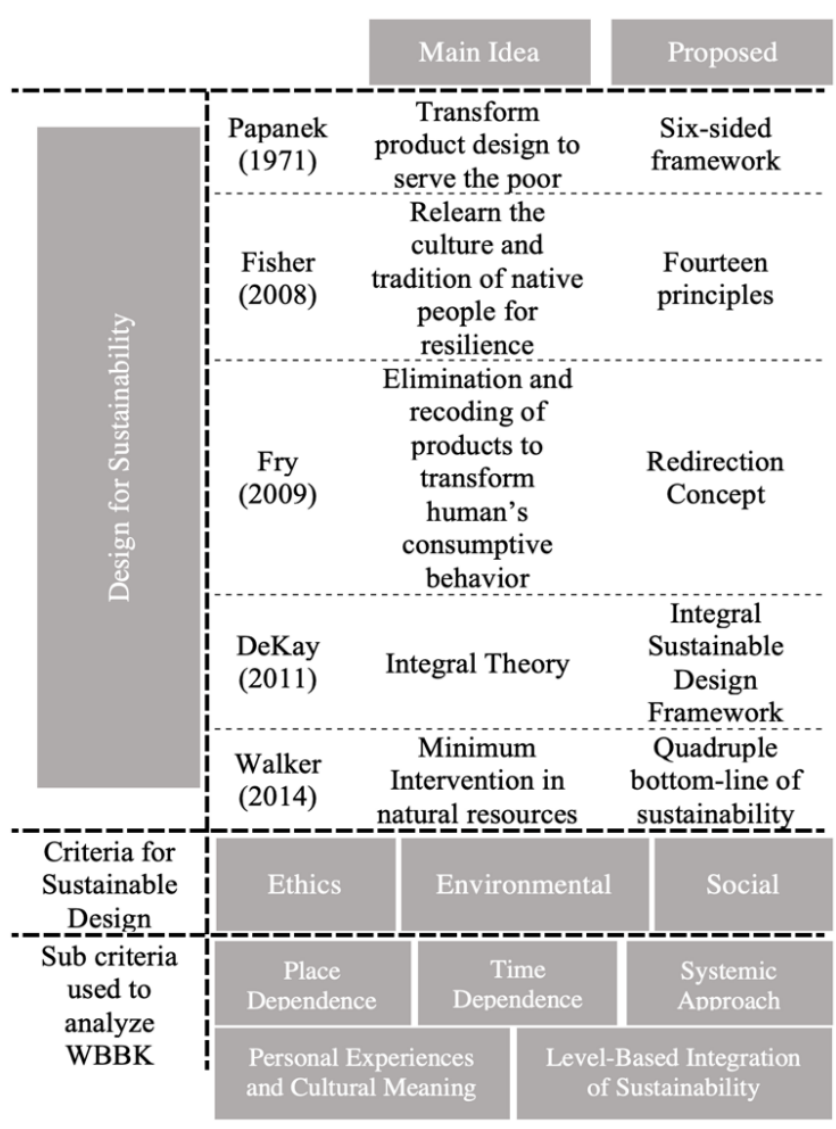

Figure 2. WBBK framework of analysis 


\subsection{Place dependence}

As in section 5.1, one of the main criteria for sustainable design is ethical judgment emphasized by Papanek, Fry, Fisher, and Walker. According to the definitions of the four thinkers, an ethical design would drive the design solution to become environmentally responsible and socially just. This results in a design that is specific to its place and culture, one that results in an optimum solution (to do the most with the least), and that considers the impact and meaning of the design in a larger context. Whereas in the case of World Bank Kabul, most solutions are centered on green materials and green technologies, which are rather general solutions. Although these technical solutions are aimed to reduce environmental harm [26], sustainability requires the design to be expressive of and responsive towards its socio-economic context [15]. Moreover, Orr [27] defines design as, “....not just about how we make things, but rather how we make things that fit harmoniously in an ecological, cultural, and moral context". Similarly Keitsch [20], Sauerbruch and Hutton [28] talked about an architecture where the climate is the generating factor for the design and where the design reflects culture and society and is valued by humans.

\subsection{Time dependence}

Accounting for the time dependent nature of sustainability is another important point recalled by designers to address sustainability in design [7, 15, 17]. In this regard, Berardi [7] calls for buildings to be adaptable and flexible, promoting resiliency to easily accommodate the new requirements that evolve with time. Looking at WBBK, it barely provides any adaptable, flexible, and self-sufficient design strategies that can overcome the demands of a changing world. One of the strategies in design that can contribute to the resilience of a building is the use of passive features that can optimize thermal comfort and reduce the dependence of the building on external supply systems [29]. However, although the WBBK building uses solar panels to generate electricity, it only provides $7 \%$ of the building's energy consumption which is insignificant.

Moreover, the building totally relies on mechanical Heating, Ventilating, Air conditioning, and Cooling (HVAC) system for heating and cooling purposes [25]. Brand [30] defines adaptability as the building's ability to reshape and refine itself according to the changing demands of its occupants; that would result in its longevity. This he believes is achievable through a design that is a result of the collaboration between the users and the technical design team. Like Walker [18], he calls for modest design with the least intervention in natural resources.

\subsection{Systemic approach}

Conte and Monno [31] emphasize the importance of evaluating the sustainable performance of a building on an urban scale to assess the building's contribution towards the sustainability of its context and the consideration of various social and ecological impacts on the building design. They argue that isolating the building from its context in terms of its sustainability assessment will lead to its high dependence on eco-technologies to enhance the performance of the building.

In the same way, DeKay [19] locates LEED-certified buildings in the UR quadrant (behavior perspective) of his integral sustainable design framework (consisting of four perspectives, namely behavior, systems, experiences, and cultures). He argues that LEED-certified buildings mostly rely on enhancing the performance of the building by upgrading the parts of it, rather than locating the building in a social and ecological system. Kemp [32] defines sustainability innovation to be dependent on "aspects of use" that rely on "contextual conditions"; thus, requiring sustainability to be assessed on a system basis according to "aspects of use" rather than technology basis.

\subsection{Personal experiences and cultural meaning}

The four-nexus framework for sustainable design, by Mark Dekay, gives equal importance to subjective qualities of design as much as for the objective aspects [19]. Where the objective aspects of sustainable design relate to the environmental performance of design, subjective qualities require considering the personal experiences of the users and the symbolic meaning creating for them. As with DeKay [19], Walker [18] also discusses the importance of the meaning of a product, its connectedness to people, and addressing the deep human perceptions.

Although several thinkers including DeKay have criticized the LEED-certified buildings to be technically centered while ignoring the personal experiences of the occupants and the cultural and symbolic meaning created for the society. This seems to be the case in the WBBK, where the developers have not provided any information about the experiences and meaning created by the architecture of the project [25].

Although, the role of LEED and other sustainable building assessment tools are appreciated by authors to promote the importance of sustainable design [31], but creating "rich human experiences" and "mean making stories" through introducing Nature in the design are also important aspects of sustainable design to create a relationship between people and Nature [18, 19].

Furthermore, Cucuzzella also emphasizes the aesthetics of sustainable architecture and introduces an analytical framework to read and understand the quality of sustainable design beyond its environmental performance [33]. Moreover, (Papanek, 1971) defines aesthetics in sustainable design as an intrinsic part of function not just a superficial appearance (see section 4.1).

\subsection{Level-based Integration of sustainability in design}

Sustainability in design disciplines is implemented at various levels [8, 10, 14, 34-36]. Keitsch defines sustainable design implementation at three levels namely micro level, meso level, and macro level. Her definition of the three levels shares ground with the definition provided by Brezet [36, 37], and many more. Where the complexity level increases from making incremental changes in product, to designing new products, processes, and services, to a change in practice that requires new action structures and introduces new consumption patterns. Writers in Refs. [16-18], require transformational change (innovative design) at the system level as a sustainable design solution i.e., macro level; where design practice transforms human behavior and that needs an understanding of socio-cultural practices.

As Fry [17] recalls, "Design is never culturally neutral - it always transports socio-cultural values. Equally, what it brings into being always designs beyond mere function. Design is 
thus a means as well as a product of cultural production, as the history of both architecture and technology confirm".

Vezzoli et al. [8], Ceschin and Gaziulusoy [10] describe how design for sustainability has evolved from a product level, rooted in technical perspective to considering socio-technical issues that cover systemic approaches. Higher levels of integrating sustainability in design discipline are usually associated with tackling social and ecological issues and creating positive impacts on societies and the environment $[8$, 34, 38, 39].

As has been observed in the case of WBBK, it could be argued that the designs are mostly incremental improvements applied to materials and services to reduce environmental impact. Thus, according to $[8,10,14,34-36]$, this places the design of the building only at the micro-level of achieving sustainability.

\section{RESULTS AND DISCUSSION}

Implementing sustainability in the design of the built environment is a new concept in Afghanistan. As part of Afghanistan's commitment to the UN's SDGs, it is important for the country to enhance its built environment towards environmental and social sustainability. However, this requires a general understanding of the concepts of sustainability within the design disciplines and a thorough study of certain cases to learn and to build upon them.

This study analyzed and compared five of the most influential books on sustainable design spanning from the 20th century to the 21 st century, to understand the concept of designing for sustainability. The aim of the study was to explore sustainable and appropriate ways of design for the built environment in Afghanistan.

The study then examined the sustainable strategies applied in the design of the first LEED-certified building in Afghanistan (WBBK), provided by the developers, in the light of the findings from these prominent publications. The findings from the case study (WBBK) in (section 3) compared with the analysis from prominent publications on sustainability design in (section 4), helped to draw out major issues required for the design of a sustainable built environment in the context of Afghanistan (section 5).

The study revealed that although the WBBK promoted the idea of sustainable building in the country, it certainly lacks several criteria which is essential to enhance the built environment towards a more holistic sustainable future. According to the findings, the major issues are: 1). Its high dependence on eco-technologies to reduce environmental impact rather than designing in relation to social and ecological systems. 2). Its shortfall of providing a resilient design that is self-sufficient, flexible, and adaptive. 3). Its shortfall in creating aesthetic experiences and cultural meaning.

\section{CONCLUSION}

Based on the findings of the study; it is concluded that to create a framework for the sustainable design of the built environment, it is not enough to rely on global practices of sustainability (such as LEED certification) and technological improvements. Rather the requirements of local context and user values are an essential ingredient of sustainable design.
Consequently, the higher levels of integrating sustainability in design are associated with human and ecological involvement. Notwithstanding the importance of technology, consideration of cultural, social, and ecological factors in design is essential for a more holistic sustainable built environment. Moreover, an innovative sustainable design is meant to create a positive impact on society and ecology and tackle societal problems. Thus, designing to reduce environmental harm and achieving occupant satisfaction should be considered as a part of a larger aim to enhance social and environmental systems in the country. Therefore, an integrated and holistic approach to design is required to achieve a sustainable and appropriate built environment. A set of recommendations to design for sustainability are provided as follows:

(1) Learning from the local built environment and building upon them to design for the future.

(2) Adapting to the present conditions and planning for the future ecological/social challenges (adaptive, flexible, and self-sufficient design).

(3) Embracing ethical and moral values for optimum resource consumption (differentiating between need and want) as well as designing to create a positive impact.

(4) Understanding the social, cultural, and ecological context as important aspects of designing for sustainability.

(5) Realizing sustainability as a process in design that deals with problems at various scales and considers the interlinkage between them, realizing the long-term and indirect impacts of the proposed solutions (system thinking).

(6) Adopting an integrated holistic design approach that promotes social interaction between various stakeholders.

(7) Designing for practical needs (social and environmental problems) as well as appreciating the connectedness of design with people and their culture (subjective qualities).

(8) Appreciating the local sources and local technologies for design (e.g., renewable energy, local craft).

\section{ACKNOWLEDGMENT}

The work is supported by Universiti Teknologi Malaysia, Skudai through the UTMER Grant entitled 'Spatial Design of Sustainable and Resilient Built Environment through Metric Analytics framework of Sustainable Development Goals (SDG)' (Q.J130000.3852.19J86)

\section{REFERENCES}

[1] Caiado, R.G.G., Filho, W.L., Quelhas, O.L.G., de Mattos Nascimento, D.L., Ávila, L.V. (2018). A literature-based review on potentials and constraints in the implementation of the sustainable development goals. J. Clean. $\quad$ Prod., 198: 1276-1288. https://doi.org/10.1016/j.jclepro.2018.07.102

[2] Olawumi, T.O., Chan, D.W.M. (2018). A scient metric review of global research on sustainability and sustainable development. J. Clean. Prod., 183: 231-250. https://doi.org/10.1016/j.jclepro.2018.02.162

[3] Recuero, L. (2018). A preliminary assessment of the indicators for Sustainable Development Goal (SDG) 14 "Conserve and sustainably use the oceans, seas and marine resources for sustainable development". Marine Policy, 98: 47-57. 
[4] Lazar, N., Chithra, K. (2020). A comprehensive literature review on development of Building Sustainability Assessment Systems. Journal of Building Engineering, 32: 101450. https://doi.org/10.1016/j.jobe.2020.101450

[5] Byrne, S. (2020). World Bank, Kabul brings green building to Afghanistan as its LEED Earth recipient. GBCI. https://www.gbci.org/world-bank-kabul-bringsgreen-building-afghanistan-its-leed-earth-recipient, accessed on May 01, 2020.

[6] Baumann, H., Boons, F., Bragd, A. (2002). Mapping the green product development field: Engineering, policy and business perspectives. J. Clean. Prod., 10(5): 409425. https://doi.org/10.1016/S0959-6526(02)00015-X

[7] Berardi, U. (2013). Clarifying the new interpretations of the concept of sustainable building. Sustain. Cities Soc., 8: 72-78. https://doi.org/10.1016/j.scs.2013.01.008

[8] Vezzoli, C., Ceschin, F., Osanjo,L., et al. (2018). Design for sustainability: An introduction. In Designing Sustainable Energy for All, Springer Verlag, pp. 103-124. https://doi.org/10.1007/978-3-319-70223-0_5

[9] Keitsch, M. (2012). Sustainable design: A brief appraisal of its main concepts. Sustain. Dev., 20(3): 180-188. https://doi.org/10.1002/sd.1534

[10] Ceschin, F., Gaziulusoy, I. (2016). Evolution of design for sustainability: From product design to design for system innovations and transitions. Des. Stud., 47: 118163. https://doi.org/10.1016/j.destud.2016.09.002

[11] Goubran, S., Cucuzzella, C. (2019). Integrating the sustainable development goals in building projects. J. Sustain. Res., 1: e190010. https://doi.org/10.20900/jsr20190010

[12] Ramos, T.B., Caeiro, S., Disterheft, A. et al. (2020). Rethinking sustainability: Questioning old perspectives and developing new ones. J. Clean. Prod., 258: 120769. https://doi.org/10.1016/j.jclepro.2020.120769

[13] Sassi, P. (2006). Strategies for Sustainable Architecture (1st ed.). Taylor and Francis. https://doi.org/10.4324/9780203480106

[14] Adams, R., Jeanrenaud, S., Bessant, J., Denyer, D., Overy, P. (2016). Sustainability-oriented Innovation: A Systematic Review. Int. J. Manag. Rev., 18(2): 180-205. https://doi.org/10.1111/ijmr.12068

[15] Papanek, V. (1971). Design for the Real World: Human Ecology and Social Change. New York: Pantheon Books.

[16] Fisher, T. (2008). Architectural Design and Ethics: Tools for Survival (1st Ed.). Taylor and Francis, London. https://doi.org/10.4324/9780080569321

[17] Fry, T. (2009). Design Futuring: Sustainability, Ethics and New Practice. Berg, New York.

[18] Walker, S. (2014). Designing Sustainability: Making Radical Changes in a Material World. Routledge, London. https://doi.org/10.4324/9781315797328

[19] DeKay, M. (2011). Integral Sustainable Design: Transformative Perspectives. Routledge, London. https://doi.org/10.4324/9781849775366

[20] Keitsch, M. (2015). Sustainable design: concepts, methods and practices. In Routledge International Handbook of Sustainable Development, M. Redclift and D. Springet, Eds. Routledge, pp. 164-178.

[21] Shao, J. (2013). Sustainable strategies applied on commercial architecture in Australia. Front. Archit. Res., 2(3): 362-372 https://doi.org/10.1016/j.foar.2013.04.005
[22] Wen, B., Musa, N., Onn, C.C., Ramesh, S., Liang, L.H., Wang, W. (2020). Evolution of sustainability in global green building rating tools. J. Clean. Prod., 259: 120912. https://doi.org/10.1016/j.jclepro.2020.120912

[23] Szibbo, N. (2016). Lessons for LEED® for neighborhood development, social equity, and affordable housing. J. Am. Plan. Assoc., 82(1): 37-49. https://doi.org/10.1080/01944363.2015.1110709

[24] Berardi, U. (2015). Sustainability assessments of buildings, communities, and cities. Assessing and Measuring Environmental Impact and Sustainability, pp. 497-545. https://doi.org/10.1016/B978-0-12-799968$5.00015-4$

[25] EN3, “Case Study: World Bank, Kabul,” EN3, A Carbon Neutral Company, 2019.

[26] Cole, R.J. (2012). Transitioning from green to regenerative design. Build. Res. Inf., 40(1): 39-53. https://doi.org/10.1080/09613218.2011.610608

[27] Orr, D. (2007). Architecture, Ecological Design, and Human Ecology. In the Green Braid, K. Tanzer and R. Longoria, Eds., Routledge, London and New York, pp. 15-33. ISBN 0-203-96488-8.

[28] Sauerbruch, M., Hutton, L. (2011). What Does Sustainability Look Like? In Aesthetics of Sustainable Architecture, S. Lee, Ed. Rotterdam, pp. 41-49. ISBN 9789064507526

[29] Hewitt, E., Oberg, A., Coronado, C., Andrews, C. (2019). Assessing "green" and "resilient" building features using a purposeful systems approach. Sustain. Cities Soc., 48: 101546. https://doi.org/10.1016/j.scs.2019.101546

[30] Brand, S. (1994). How Buildings Learn: What Happens After They're Built. Penguin Books.

[31] Conte, E., Monno, V. (2012). Beyond the buildingcentric approach: A vision for an integrated evaluation of sustainable buildings. Environ. Impact Assess. Rev., 34: 31-40. https://doi.org/10.1016/j.eiar.2011.12.003

[32] Kemp, R. (2010). Sustainable technologies do not exist! EKONOMIAZ. Revista vasca de Economía, 75(4): 2239.

[33] Cucuzzella, C. (2020). Analyzing Eco-Architecture: Beyond Performance. JFD inc. Montreal (Quebec): Bibliothèque et Archives Nationales du Québec.

[34] Joore, P., Brezet, H. (2015). A multilevel design model: The mutual relationship between product-service system development and societal change processes. J. Clean. Prod., 97: 92-105. https://doi.org/10.1016/j.jclepro.2014.06.043

[35] Keitsch, M. (2012). Sustainable architecture, design and housing. Sustain. Dev., 20: 141-145. https://doi.org/10.1002/sd.1530

[36] Brezet, H. (1997). Dynamics in ecodesign practice. Industry and Environment, 20(1): 21-24.

[37] Brezet, H., van Hemel, C. (1997). Ecodesign: A promising approach to sustainable production and consumption. UNEP.

[38] Loh, S., Foth, M., Caldwell, G.A., Garcia-Hansen, V., Thomson, M. (2020). A more-than-human perspective on understanding the performance of the built environment. Archit. Sci. Rev., 63(3-4): 372-383. https://doi.org/10.1080/00038628.2019.1708258

[39] Birkeland, J. (2020). Net-positive Design and Sustainable Urban Development. Routledge, New York. https://doi.org/10.4324/9780429290213 